\title{
Decentralized project management concept for schedule-critical space projects
}

\author{
Jaime Campos ${ }^{1} \cdot$ Philip Ferguson ${ }^{1,2}$ (B)
}

Received: 26 January 2021 / Revised: 15 May 2021 / Accepted: 6 July 2021 / Published online: 20 July 2021

(c) Shanghai Jiao Tong University 2021

\begin{abstract}
The Apollo moon missions of the 1960s pioneered the classic phased approach to space mission management. While successful at the time, this rigid and inflexible management philosophy has become synonymous with cost and schedule overruns of most high-profile space missions. The software industry has recently adopted modern, more flexible project management techniques based on "lean-agile" methods that enable team collaboration and communication through distributed task and schedule management, online document sharing and rolling-wave planning. However, due to the inherent schedule complexities of hardware development and the firm constraints of design review and launch timelines, flexible project management frameworks have not been widely adopted for space mission management. This paper presents a modified version of the traditional agile management philosophy, adapted to the unique needs of the space industry. A recent satellite development project was managed using the new modified-agile approach, while collecting project hours and task durations. Comparisons were made between this new style of space project management and a recently completed satellite development project using traditional space project management techniques. Results show that the new management approach reduced strain on the project team, improved overall productivity, and maintained a more level task loading when compared to the traditional management approach. This paper also illustrates how the new management approach can enable project resilience to change by analyzing its response to the labor disruptions caused by the COVID-19 pandemic.
\end{abstract}

Keywords CubeSats $\cdot$ Systems engineering $\cdot$ Agile philosophy $\cdot$ Adaptable teams $\cdot$ Industry projects $\cdot$ Resource management

\section{Introduction}

Traditional space projects, first developed for the Apollo program, often follow a rigid structure [5,27]. This traditional approach is built around strict deadlines for design reviews, hardware delivery and launch, which requires detailed and firm work plans before any work can proceed, making it difficult to adapt to change [15].

Richards [24] argues that adherence to tradition is the largest factor that drives up space project costs, noting

Philip Ferguson

philip.ferguson@umanitoba.ca

Jaime Campos

camposj1@myumanitoba.ca

1 University of Manitoba, Department of Mechanical Engineering, 75 Chancellor's Circle, Winnipeg, MB R3T 5V6, Canada

2 NSERC / Magellan Aerospace Industrial Research Chair in Satellite Engineering, Winnipeg, MB, Canada that the need for first-time success causes extensive and expensive process control. Managers are expected to create detailed project plans from the beginning to the end of the project, which must be continuously monitored throughout the project. Metrics such as Earned Value Management (EVM) are traditionally used to track the project progress [22], however, these metrics are often unrelated to the work the engineering teams are performing, leading to a disconnect between project management and the team carrying out the work [29]. The disconnection from the engineering team and the inability to modify the work plan, result in a suffocating rigidity that limits the ability of a team to react to new information, unforeseen circumstances, and other external factors.

These challenges can be observed in the cost and schedule increases of flagship space missions. For example, the James Webb Telescope project had a budget overrun of 1,000\% [3]. Other scholars have pointed to space project management as the root cause for technical failures such as NASA's Mars Climate Orbiter [26]. These cases have sparked consid- 
erable academic interest in the ability to develop adaptable project management approaches for complex space missions $[12,25]$. One method to reduce project cost overruns is to move away from the rigid traditional management method and embrace new flexible project management philosophies.

The considerable focus in creating an adaptive project management approach can also be applied to technical aspects of the project, allowing for a systems engineering structure that can tolerate changes. Boswell et al. [4] note that both project management and systems engineering use similar tools to organize and plan necessary project work, but the overlap can cause confusion when dividing roles and responsibilities. However, [8] argue that the similarity provides sufficient common ground for systems engineering to incorporate developments in adaptive project planning. With Agile tools and methods, the technical team can create a space hardware development project that adapts to internal and external unforeseen factors. Campos and Ferguson combined project management and system engineering using verification activities as a progress metric instead of EVM. Verification activities are concisely defined technical milestones that are meaningful to all project members, facilitating communication between all stakeholders in the spirit of the Agile Manifesto [2].

CubeSats, also known as nanosatellites, provide a low-risk and low-cost opportunity for various science and technology missions $[10,30]$. CubeSats are also a low-risk and valuable opportunity to experiment with the management method of a space project. This study, therefore, turns to management philosophies and applications that have been developed outside of the space sector and applies them to a CubeSat project systems engineering effort. The Agile Philosophy $[2,12]$ increases adaptability without impacting value to the customer. Other approaches that focus on reducing waste in project management include Lean Manufacturing [23] and Theory of Constraints [19].

This paper presents a hybrid phased-agile approach for space project management and systems engineering that provides a more accommodating structure to project change, while maintaining a schedule that adheres to the strict design review and launch milestones associated with space projects. This new management approach results in a more even distribution of tasks and better team communication when compared to traditional space project management. To demonstrate the value of this new approach, we compare and contrast empirical project health data (including labor hours and task start/end dates) from two different projects: (1) a recently completed industry satellite development project managed using traditional space project management strategies, and (2) a CubeSat project (Iris) using modern, Agile-inspired management strategies.

The primary contributions of this research include:
- A hybrid phased-agile approach to project management that is suitable for space systems engineering.

- A quantitative comparison between a traditionally managed satellite project, and a student-led satellite project using the proposed hybrid phased-agile approach. The quantitative study considers each team's labor hours [7], task durations, and work hours per week or day.

- A quantitative evaluation of how the proposed hybrid phased-agile management approach handled the labor and task disruptions due to the COVID-19 pandemic, which demonstrated the ability of a project to adapt to unpredictable external demands.

\section{Background}

\subsection{Traditional phased approach for space project management}

Traditionally managed space projects use a phased approach, as outlined by the NASA Systems Engineering Handbook [15]. The phases are organized according to the nature of the work, and follow a "design, build, test, and launch" pattern. The phased approach allows for a low level of adaptability, because each phase builds upon the completed work from the previous phase. Thus, subsequent phases cannot easily alter spacecraft designs without changing decisions made in prior phases. Carson [9] notes that this approach allows for the careful and incremental completion of work that enables the project team to ensure the system is designed as a whole. The project phases are:

- Pre-A-initial concept studies

- A-concept development

- B-preliminary design

- C-critical design

- D—assembly, integration, and testing (AIT)

- E-operations

- F-closeout

Each phase concludes with an end-of-phase review, providing a vital communication point for all stakeholders to ensure the design is in accordance with goals and expectations. In addition, the end-of-phase reviews act as project decision points, providing project sponsors with valuable control over the technical progress, and ensuring that the project team is ready to undertake the next phase. This process is followed from project conception (in pre-phase A) through launch and disposal (at the end of the mission).

Project progress is traditionally measured through EVM as outlined by the Project Management Body of Knowledge [22]. EVM is defined as comparing the following three primary economic metrics to monitor the project health: 
- Planned value (PV) — authorized budget assigned to scheduled work

- Earned value (EV)) — the measure of work completed in terms of budget authorized

- Actual cost (AC) - the cost of the work performed on an activity

EVM provides managers and sponsors with a meaningful method for understanding the project progress, but requires the existence of a pre-established detailed plan to compare the three metrics. Cabri and Griffiths [6] note that a project needs to meet very specific criteria before beginning work to implement EVM, including a fully detailed plan, budget, and schedule. The combination of the traditional phased approach and the EVM method provides space projects with valuable structure. However, EVM can also cause inflexibility due to the need to re-baseline the detailed schedule when changes or corrective actions are needed. Such inflexibility can be very expensive if, and when, a project needs to adapt to changes.

\subsection{Alternatives to traditional project management for space projects}

Although the traditional phased approach provides valuable structure to modern space projects, the space sector seeks methods to reduce project cost and development time. The desire to change from large flagship missions to affordable space projects appears in NASA's lessons learned from their efforts to develop "faster-better-cheaper" projects [20]. These lessons call for using concurrent engineering approaches, commercial off-the-shelf components, design inheritance, and frequent reviews for early fault detection.

The space sector has developed different methods to improve project team communication by implementing concurrent engineering. Concurrent engineering is a planning approach that involves all project disciplines (such as design and manufacturing) from the beginning of the project [17]. Applying all project elements from the start enables coordinated long-term project planning between all team members and increases team communication. Doerksen [11] discusses an academic team's experiences using a concurrent engineering facility integrated with information technology. Doerksen et al. noted benefits including a shortened learning curve for students, synchronization with academic schedules, and the ability to retain knowledge during team turn-over.

Aerospace projects have adopted the scrum planning method from the software industry as a method to increase visibility and control. Dwyer [12] defined scrum as an iterative management approach that uses short time windows to monitor progress and implement changes based on customer and team feedback. The short time windows provide the project leads with much more control over the project, facilitating corrective actions or applying new ideas. At the beginning of each time window, the team reviews the remaining work and updates tasks based on feedback or changes during previous windows. In addition, because it is a team review, each team member is aware of each other's availability and work load.

Although scrum originated in the software sector, the aerospace industry has experimented with this approach. Petrini and Muniz [21] studied the impact of scrum management on an aircraft manufacturer during test development activities, finding that the team had greater processing efficiency and performed close to predicted targets. Similarly, [13] investigated the effectiveness of scrum in the development of space hardware, noting that although the team was unable to meet their work targets for most time windows, they were able to deliver the product for testing on time. Garzaniti et al. found that missed work targets are common for teams adopting the Agile Philosophy. The causes are inexperience with system engineering complexity and inter-dependency for hardware manufacturing.

Dwyer [12] investigated methods to apply the Agile Philosophy, a work philosophy that focuses on adapting to change over adhering to a rigid plan, to mechatronic projects consisting of small multi-disciplinary teams. Dwyer's Agile method integrates the feature-oriented and incremental approach found in hardware development while maintaining a phased approach. He undertook two case studies to validate his design, finding that projects had insufficient collaboration, iteration, and sponsor feedback. However, Dwyer noted that a more rigorous approach is needed for his full verification.

Huang et al. [16] provide a blueprint of their CubeSat project management plan that implements the Agile Philosophy and scrum planning. Huang et al. recommend co-location, interactive design reviews, tailored processes, and early prototype testing to find design faults. Their recommendations are similar to ideas found in the "fasterbetter-cheaper" lessons learned [20], but did not empirically verify the impact on project cost and schedule.

This study evaluates an adaptive phased-agile approach to project management for a student-led CubeSat project (Iris) and quantitatively compares it with a traditionally managed industry project. The following section provides an overview of the research methodology for this project, which includes a description of the adaptive management methods and tools used for a student-led CubeSat project (Iris).

\section{Research methodology}

This study collected data from the Iris project, a studentled CubeSat development project that implemented a hybrid phased-agile approach, and compared it to a traditionally managed project. The impact of the hybrid approach was 
analyzed through labor hours and task durations. However, to fully understand the analysis, an overview of the Iris approach is presented in the following section.

\subsection{Student CubeSat project management approach}

The Iris project provides an ideal opportunity to experiment with project management approaches to create a highly adaptive management structure for a satellite project. Since the Iris team was mostly comprised of students, with changing availability due to classes and off-project work, the Iris project required an adaptable schedule to provide the team with the flexibility to undertake work when possible. Although the project sponsor requires the Iris project to adhere to the traditional phases described previously, the sponsors allow alternative project planning and reporting methods. The Iris team received guidance from Playbook [14], a Lean-Agile project management resource, when developing the hybrid phased-agile approach. The Iris team was trained to identify four sources of delay:

- Incorrect priorities - not working on a critical path (high priority) task when one is available

- Multitasking — resources dividing their attention among two tasks, increasing the completion time for both tasks

- Unavailable resources - if resources or tools are unavailable, the task will be delayed

- Technical difficulties-technical problems that are present in every project

While project management techniques cannot typically mitigate technical difficulties, planning and strong communication can mitigate the first three items. To promote team communication, the CubeSat team adopted the Agile Philosophy approach, where each team member is encouraged to communicate and share ideas to find the best technical solution. Each subsystem lead is responsible for developing their subsystem's schedule, which decentralizes the project management tasks and transforms the project manager and systems engineering lead into a guiding and supporting role.

Delays due to incorrect priorities were mitigated using a central data management method, that took the form of a Wikipedia-inspired website (wiki) that acted as technical documentation. This wiki provided an easy to record and update database that was accessible to all team members, even if they were off-site. Any team member was able to update the wiki, maintaining an accurate up-to-date record. Therefore, any team member could review the wiki at any time to understand the current state of the project, identify areas that required support, and assess their priorities.

Multitasking was controlled by implementing a Kanban board to restrict team members to work on only one task at a time. When a person multitasks, their focus switches back and forth between the tasks, losing time in each switch. To mitigate this, the Iris project required that team members schedule one active task at a time, to promote focus and productivity. Task scheduling was recorded directly into Playbook, enabling the management team to monitor the work load of individual resources.

Unavailable resources were monitored using a scruminspired planning method, called "rolling wave" by Playbook, where an outline of the project schedule was created and detailed as the project continued. Rolling wave planning enables project teams to create schedules that are easily adaptable and can incorporate new information at any phase of the project. Each team member was responsible for creating and updating their own schedules, which were updated on a weekly basis based on completed work and new information. The team had frequent meetings to communicate task progress and current schedules, ensuring a team-wide awareness of resource availability. The Iris team adhered to the project sponsor's phased approach requirements by creating detailed schedules for the subsequent phase to prepare for end-of-the-phase reviews. This approach produced a schedule that reflected the project's current state without requiring large time investments in deconstructing and reshaping the original schedule.

The CubeSat team used a theory Y [1] management approach, which allowed teams to self-organize and direct project labor, thereby changing the roles of the project manager and systems engineering lead to guidance and coordination. The team used a variety of communication channels to facilitate the exchange of ideas, including a Wikipediainspired website to act as the project's documentation and data registry, which was easily accessible to the team over the Internet. To ensure the team was aware of the project's health status, Playbook was used to create a Gantt and Kanban method to easily control and monitor project schedule and task backlogs. By incorporating these approaches, the team was able to quickly identify project priorities. The team communicated their respective availability, ensuring everyone was aware of available resources and priorities.

\subsection{Project characteristics}

This research analyses data from two space projects:

Project 1: The industry project was a recently completed large satellite project, managed using the traditional rigid project management approaches. It was managed through classical EVM and often suffered from unsustainable spikes in team workload, as a result of its inability to adapt to project changes.

Project 1's management team collected the project health data on a weekly basis, which included the labor hours for that week, and the task start and end dates as a week number 
in a year. This research received the labor hours for phases B through $\mathrm{D}$, and the task start and end dates for phases $\mathrm{C}$ and D. The management data can be combined to determine the level of effort needed by the team to complete the necessary work, providing insight into how a traditionally managed project uses the development team.

Project 2: The Iris project is an ongoing student-led CubeSat development project that allows post-secondary students to design, build, and launch their own satellite mission [28]. This study implemented non-traditional management approaches for the Iris project that resulted in a highly adaptive CubeSat development project that can quickly adapt to change in an unpredictable work environment. Common changes included high team member turn-over rates and resource unavailability due to class schedule changes.

Project 2 recorded project health through self-reporting on a daily basis for phases B and the ongoing phase C. Data recorded includes task start and end days, including hours committed to each task or task segment. Although the resolution of recorded data is different from Project 1, labor hours and task dates provide valuable insight into how the team was used as the project continued.

Although Project 2 composed of students and has fewer available resources, it provides a valuable case study and blueprint for space projects. Although there is a large difference between their scope, both projects adhere to the same space systems engineering constraints. All space systems need to implement specific subsystems, such as power and communications, to ensure their missions can be completed. Since the required subsystems are common in all spacecraft, they are included as standard systems engineering training in both industry [15] and academia [18]. Although the payload defines the nature of all satellite missions, they all share the same systems engineering activities. All missions need a dedicated technical team, working subsystems and interfaces, adherence to requirements, and first-time success after launch. Since changes can occur in any project, regardless of scope, the shared characteristics of space projects create an opportunity to apply the Agile Philosophy to space systems engineering projects.

The following sections present the collected data for Project 1 using traditional project management techniques while comparing it with Project 2 (the student-led CubeSat project, Iris). The industry company used custom project management software to collect and amalgamate project health data for Project 1, while Project 2 used Playbook to collect labor hours and task completion information, providing valuable data for this study.

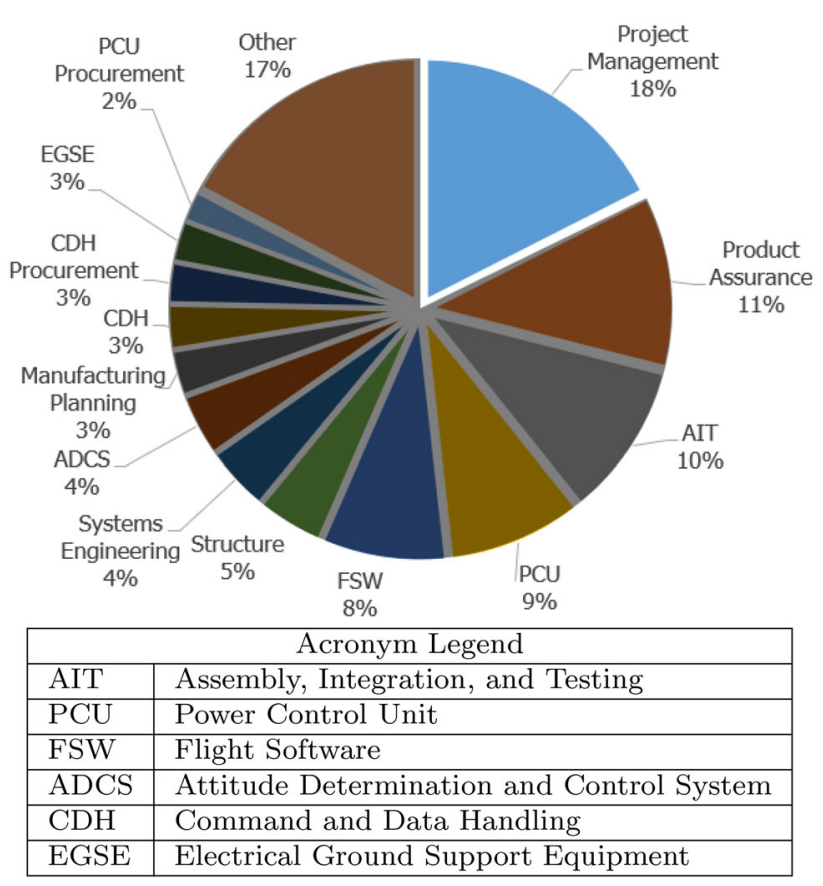

Fig. 1 Total Project 1 labor distribution (traditional project management) from phases B through D

\section{Results and discussion}

The previous section presented an overview of the traditional management approach, and the modern, more flexible project management approach used for the student project. The CubeSat project management data are compared to data received from a recently completed industry project (using traditional project management approaches) for comparison.

\subsection{Project 1 trend}

The Project 1 data from a traditionally managed industry project include labor hours and task start/end dates, demonstrating the nature of the traditional project management approach. Project 1 provided labor hours for phases B through $\mathrm{D}$, organized by the category of work (such as project management, subsystem design, or procurement). Figure 1 provides an overview of how labor hours are used in Project 1.

Our analysis found that the most extensive use of labor hours for phases B through D was direct project management, which used 18 percent of the total labor hours. This category's proportional size highlights the high level of involvement needed from the project manager to ensure project tasks are followed. The second largest category, marked "other" in Fig. 1 , is a collection of all other categories that account for less than 2 percent of the total recorded hours. To fully understand the breakdown of the demand for project management resources, each phase needs to be investigated individually. 


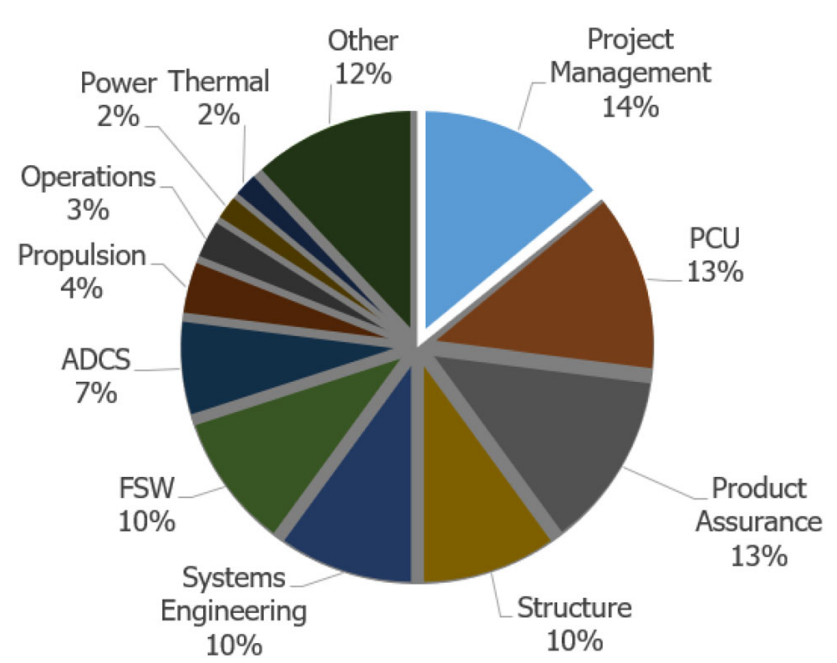

Fig. 2 Project 1 phase B labor distribution

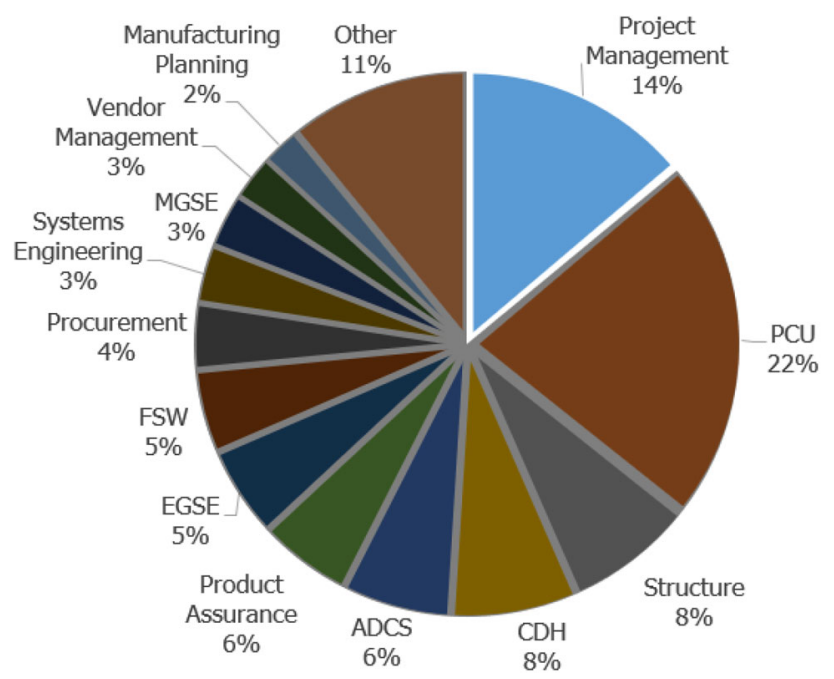

Fig. 3 Project 1 phase $\mathrm{C}$ labor distribution

Figures 2, 3 and 4 show the labor hour breakdown for phases $\mathrm{B}$ to $\mathrm{D}$, respectively.

Project management is the largest use of labor hours in all project phases, with 14 percent in phases $\mathrm{B}$ and $\mathrm{C}$, and 20 percent in phase D. This trend stems from the centralized management structure, in which project managers are involved in all aspects of the project, by planning and organizing necessary work. Project managers are responsible for monitoring the project health by developing and updating the project plan; this responsibility demands a considerable level of involvement as shown in Figs. 1 through 4. Furthermore, the demand on project management labor also risks overwhelming management resources, thus making them unavailable to address changes or incorporate new information into the schedule.

This study also received the start and end dates of each task for phases $\mathrm{C}$ and $\mathrm{D}$, which provides further insight into how

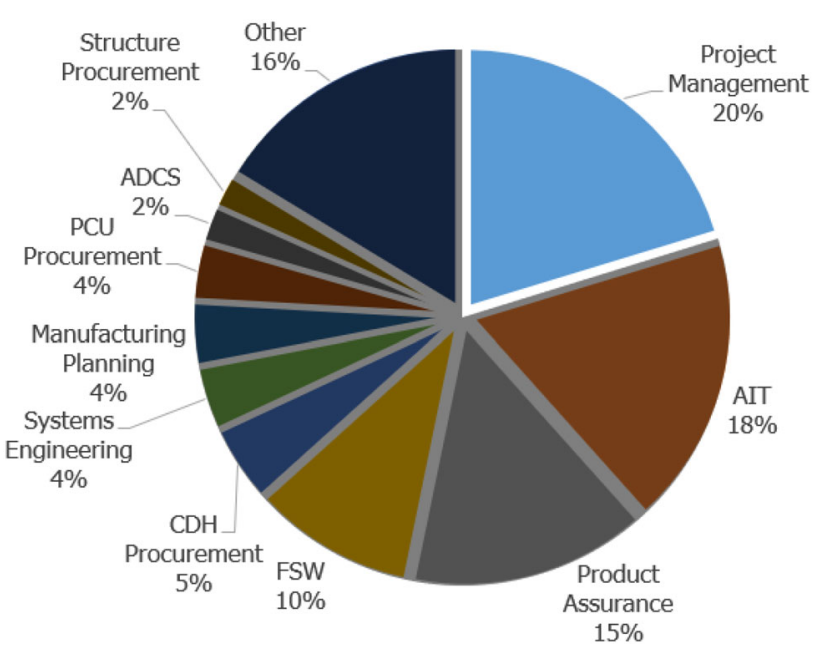

Fig. 4 Project 1 phase D labor distribution

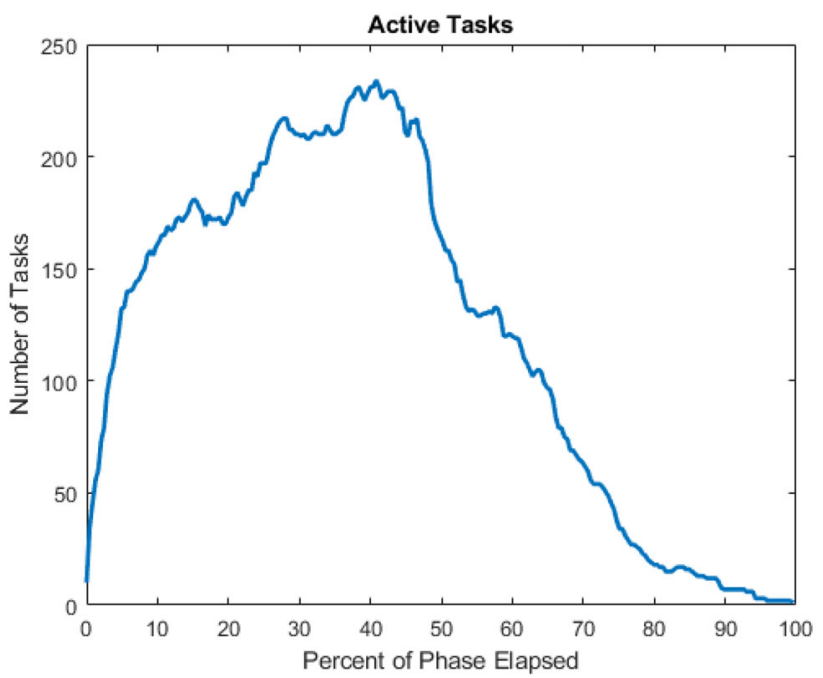

Fig. 5 Project 1 phase $\mathrm{C}$ concurrent active tasks

a large complex project evolves. Figures 5 and 6 show the quantity of concurrent tasks as the project advances through phases $C$ and $D$. Both phases have a sharp increase in work for the first 20-30 percent of the total phase time, and a long trailing end as work continues towards the end-of-phase reviews. This trend captures work growth in each phase, where concurrent active tasks grow and shrink in preparation for a review.

To determine how the traditional project management approach impacted the team for Project 1, this study combined the labor hour data with the task start and end dates to approximate the team's level of effort through each phase. The industry project recorded the week number when tasks began and ended, enabling us to create task durations. We combined the average labor hours per week for each task, and is, therefore, not accounting for variation in work times. Figures 7 and 8 provide the work hours per week to complete all tasks in phases $C$ and $D$. 


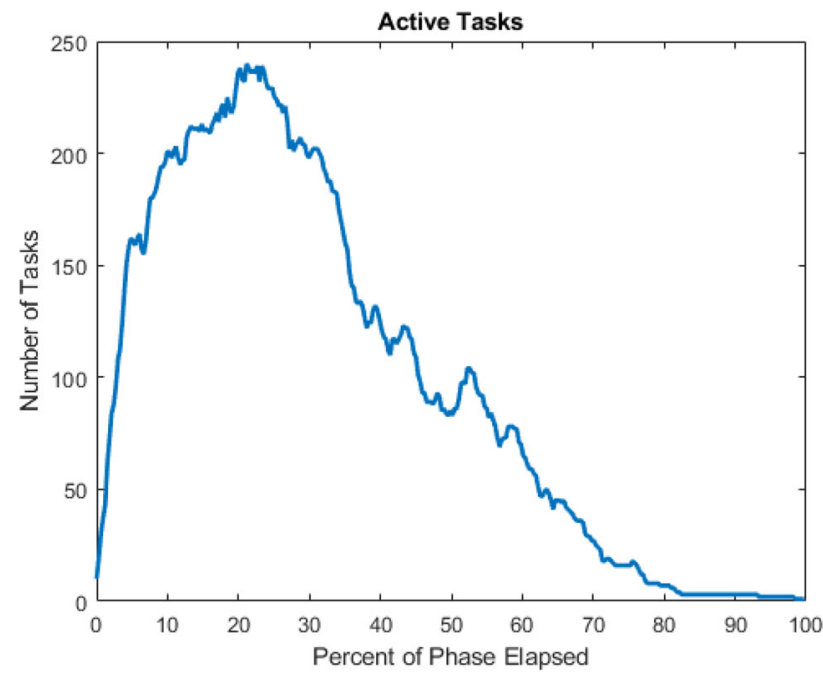

Fig. 6 Project 1 phase D concurrent active tasks

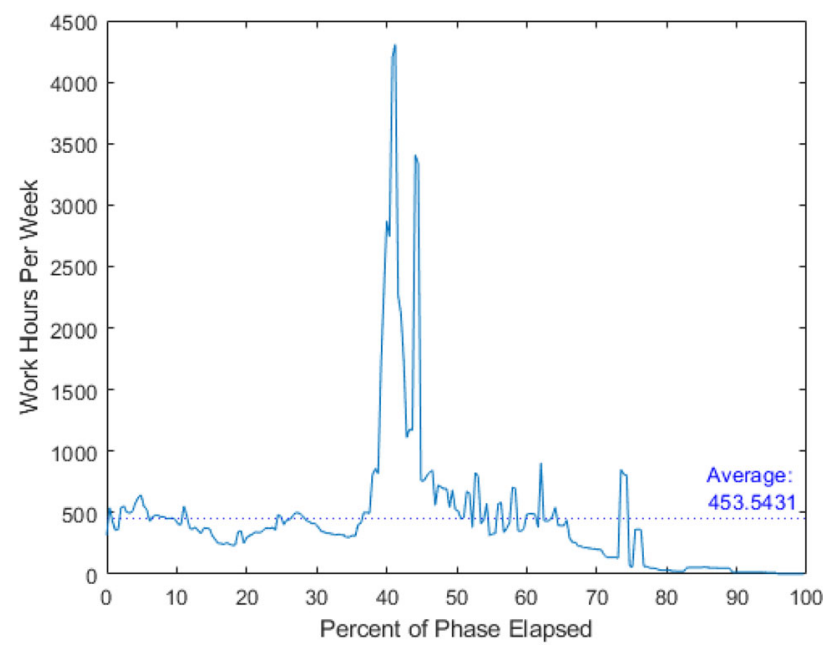

Fig. 7 Project 1 phase $\mathrm{C}$ weekly hours

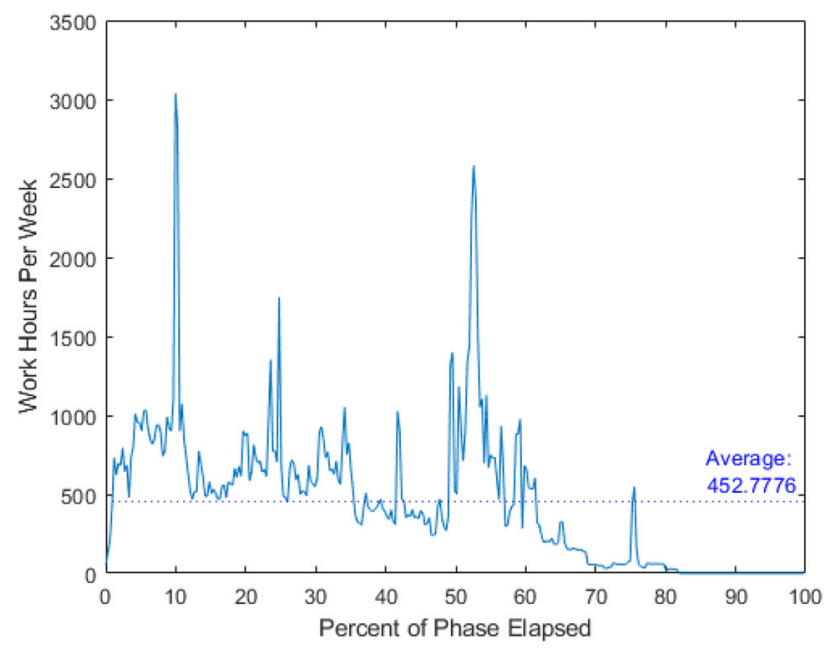

Fig. 8 Project 1 phase D weekly hours
Figures 7 and 8 show the labor hours per week and highlight the labor intensity as the phases advanced. Both phases had high peak work periods that place a large burden on project resources. The Project 1 phase $\mathrm{C}$ data (Fig. 7) remained close to the average labor hours per week, but reports a large increase in labor hours at approximately 40$50 \%$ of the elapsed phase. Phase D (Fig. 8) reported similarly high work periods throughout the phase, highlighting the nature of AIT activities. AIT activities range from subsystem assembly, satellite integration, and system-level tests which correspond with labor peaks in Fig. 8. It is likely that these peaks are indicative of workers using overtime to close out tasks, or of the recruitment of additional workers for a limited time.

This study of Project $\mathbf{1}$ data provided insight into the nature of a complex space project, managed using traditional approaches. Particular attention was paid to the demands that were made on the team's resources and time. While the traditional project management approach provides a useful framework for organizing and planning work, the data shows that high work periods occur that can impact the team. The following section presents data collected from Project 2 (the student-led CubeSat project, Iris) that used the nontraditional project management approaches described in the previous section.

\subsection{Project 2 trend}

To investigate the impact of non-traditional management approaches on a space project, this study collected labor hours, task start and end dates for the completed phase B and ongoing phase $\mathrm{C}$. This project underwent phase $\mathrm{B}$ from January 2019 to October 2019, and began Phase C in October 2019. The following data were collected from January 2019 to June 2020.

As Project 2 adopted an Agile Philosophy-inspired approach, internal team communication was an important factor in self-organization. Communication took the form of team meetings, or other informal communication approaches, that did not always involve the project manager or systems engineering lead. For the purposes of clarity in this study, the "Team Communication" category includes labor hours used for internal discussion or knowledge transfers. The category also includes technical communication between any team members. Figure 9 presents the labor distribution.

The labor used for direct project management work is 7 percent of all recorded labor hours-approximately 11 percent smaller than the industry project. The difference is marked by a lower proportional effort in directing the project, reflecting the project manager's mentorship and guidance role. 


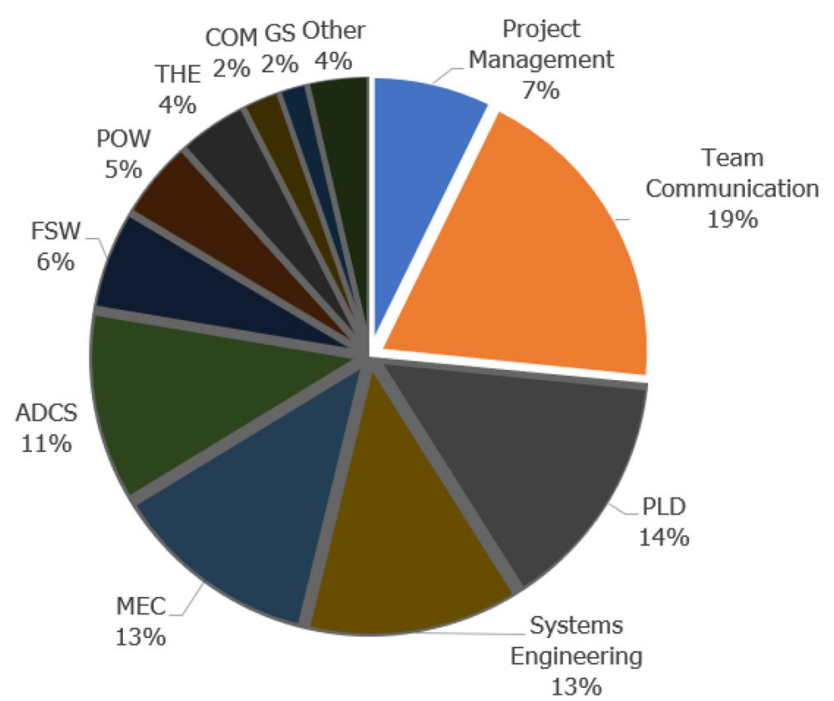

Fig. 9 Project 2 total labor distribution for phases B and C

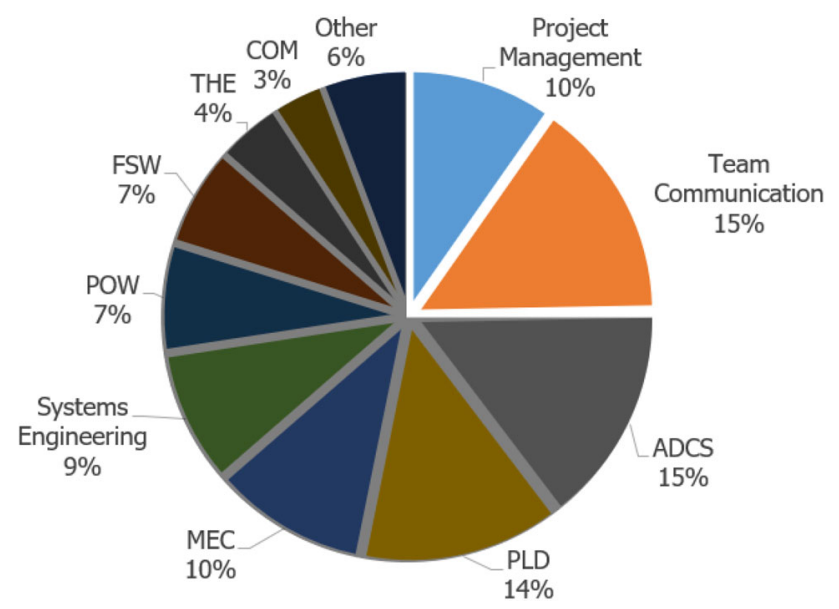

Fig. 10 Project 2 phase B labor hours

To convey a complete image of the impact of the hybrid management approach, each phase needs to be investigated individually. Figures 10 and 11 show the labor hour distribution for Project 2 in phases B and C.

For both phases, the project management category from Project 2 presents a lower use of project management labor than Project 1 in each phase, and has an increase in team communication between phases. During phase B, the Project 2 management category has approximately 10 percent of the recorded labor hours for this phase, which is 4 percent lower than the phase B project management hours in Project 1. During phase C, the Project 2 management category used 4 percent of the recorded labor hours, which is 10 percent lower than the phase $\mathrm{C}$ project management hours from Project 1.

The data also indicate that the team communication category increased between phases in Project 2. This phenomenon highlights the importance of detailed design as the project continued. The subsystems communicated with each

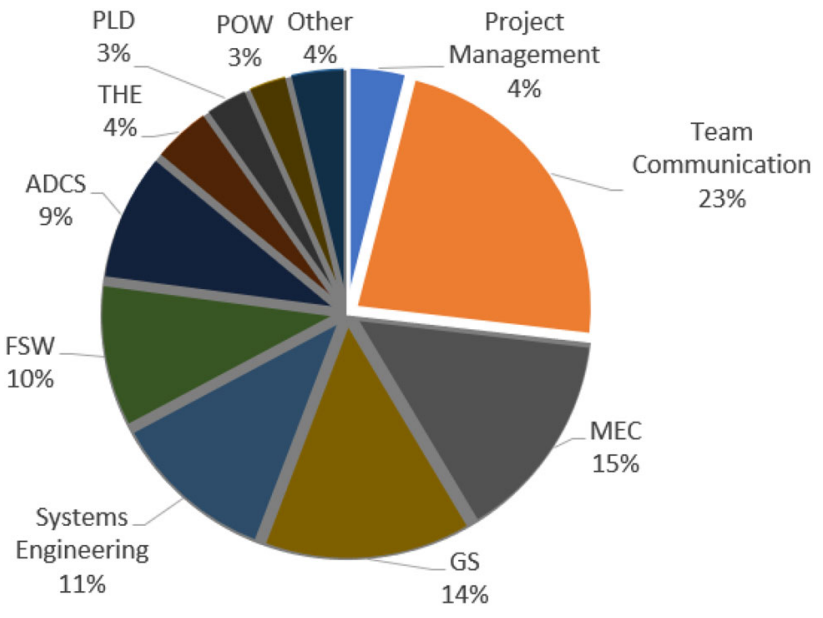

Fig. 11 Project 2 phase $\mathrm{C}$ labor hours

other to ensure harmonized interfaces, which was critical for phase $\mathrm{C}$. Phase $\mathrm{C}$ requires all design details to be ready for manufacturing in phase $\mathrm{D}$ to ensure that the outcome was a working product. During phase C, safety restrictions for the COVID-19 pandemic were established and enforced, increasing the importance of team communication to coordinate each schedule.

This study also analyzed the number of simultaneous tasks to understand the impact of the non-traditional approach on the project team, shown in Fig. 12. The recorded Project 2 phase $\mathrm{C}$ data did not experience the same pattern of a sharp increase with a trailing end as Project 1, as seen in Figs. 5 and 6. Instead, Project 2 shows a fluctuating pattern reflecting the changing availabilities of students. The distributed pattern seen in Fig. 12 demonstrates the hybrid approach's tolerance to frequent internal changes. This tolerance manifests as the team's ability to maintain a steady work throughput even as their schedules were modified. In addition, Fig. 12 captures the active task impact that COVID-19 had on Project 2, and will be discussed further in section 4.3.

To fully understand the impact on the Project 2 team, this study also investigated the daily labor hour use, shown in Fig. 13. During phase C, the Project 2 team undertook more labor hours before the implementation of COVID-19 restrictions than in the previous phase, but afterward experienced a noticeable drop in labor. In addition, during phase $\mathrm{C}$, one-quarter of the subsystem leads were busy with final thesis preparation for graduation in October 2020, which further limited the team's capacity to undertake work. However, although the ability to take on work decreased, the team was able to sustain a high number of active tasks, maintaining labor throughput. The benefit of the hybrid approach is the low demand on the team to maintain work through unpredictable environments, observed in Figs. 12 and 13. In contrast, Project 1 data (Figs. 5, 6, 7, 8) show an unsustain- 


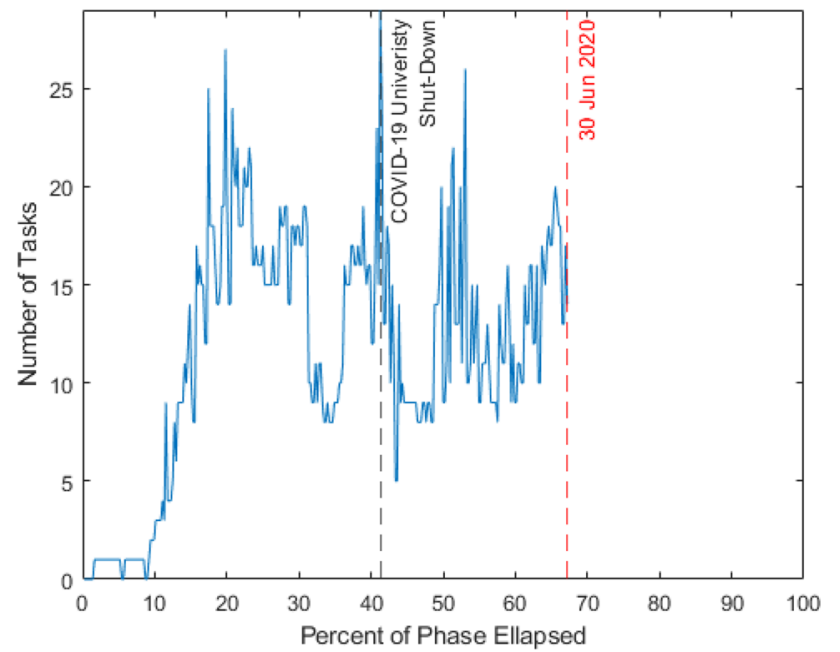

Fig. 12 Project 2 phase $\mathrm{C}$ concurrent active tasks

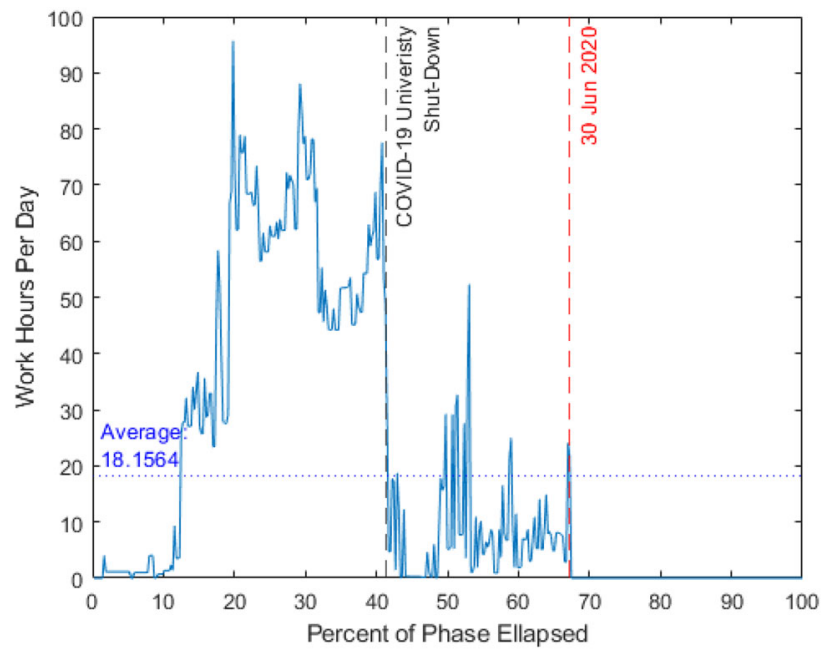

Fig. 13 Project 2 phase $\mathrm{C}$ daily hours

able labor demand on the team to maintain a steady work throughput.

\subsection{COVID-19 impact}

During Project 2's phase C, institutions began adopting social distancing protocols in response to the COVID-19 pandemic, causing a worldwide disruption of work. This large-scale disruption provided a valuable opportunity for this research by acting as a stress test for the Iris hybrid management approach. The impact can be seen in Figs. 11, 12, and 13 .

Although the team's ability to undertake work decreased when the social distancing procedures were initially implemented, they were able to sustain their active task count through the pandemic. The Project 2 team was able to take advantage of many off-site communication tools and services to self-organize and coordinate work. The need to effectively communicate during social distancing is a contributing factor to the increase in team communication from phase B (Fig. 10) to phase $\mathrm{C}$ (Fig. 11).

The institutional shutdowns also challenged the team's ability to accommodate the schedule with available resources, since manufacturing facilities were closed. The major activities planned during phase $\mathrm{C}$ included engineering model tests that required tools, operators, and special facilities. Although students and staff had restricted access to facilities, the restrictions impacted productivity and forced frequent changes. The subsystem leads continued monitoring the reopening plans, and continued updating their schedules based on new information. However, as new information on the pandemic restrictions became available, and the team grew accustomed to the situation, the team began undertaking more work. This increasing trend can be seen in Fig. 13, between 50 and $70 \%$.

The COVID-19 pandemic is an ongoing external factor that continues to change the landscape of available tools and resources, but the Iris team has been able to accommodate new information into the project. As restrictions continue to change public resources, the team continues updating our task list, schedules, and documentation to ensure up-to-date information is shared with the team. Our open and frequent communication allows us to maintain a steady work throughput as we continue to navigate unforeseen situations.

\section{Conclusion}

The Iris project (Project 2) is a CubeSat development effort that combined the traditional phased management approach with the Agile Philosophy to develop a highly adaptive management style. The Iris project implemented elements of the Agile Philosophy and Scrum planning to work efficiently with a team that has changing schedules and availabilities. Elements of Lean Manufacturing and Theory of Constraints were implemented to reduce waste. Moreover, tools were implemented to ensure that the team could work off-site, and quickly update and change schedules as new information became available.

In this paper, project management data from Iris demonstrated less management effort and a more balanced task loading when compared to a traditionally managed satellite project. In addition, the Iris project demonstrated remarkable resilience to the labor restrictions due to the COVID-19 pandemic (although there was no similar labor disruption to compare to in the traditionally managed satellite project). The results of this study suggest that it is possible to introduce space project flexibility with a decentralized management structure and improved team communication, while retaining 
strict schedule performance required for most space programs.

Funding This work was supported by the Canadian Space Agency under Grant number 17CCPMAN09. We have no financial or personal relationships with individuals or organizations that inappropriately influence our work.

\section{References}

1. Andrews GC (2013) Canadian professional engineering and geoscience practice and ethics, 5th edn. Nelson Education, Toronto

2. Beck K, Beedle M, Bennekum A, Cockburn A, Cunningham W, Fowler M, Grenning J, Highsmith J, Hunt A, Jeffries R, Kern J, Marick B, Martin RC, Mellor S, Schwaber K, Sutherland J, Thomas D (2001) Manifesto for agile software development. https://doi.org/10.1177/0149206308326772, http:// agilemanifesto.org/. Accessed $9 \mathrm{Feb} 2018$

3. Bitten RE, Shinn SA, Emmons DL (2019) Challenges and potential solutions to develop and fund NASA flagship missions. In: IEEE Aerospace Conference Proceedings 2019-March. https://doi.org/ 10.1109/AERO.2019.8741920

4. Boswell JW, Anbari FT, Via JW (2017) Systems engineering and project management: points of intersection, overlaps, and tensions. In: PICMET 2017-Portland International Conference on Management of Engineering and Technology: Technology Management for the Interconnected World, Proceedings, vol January, pp 1-6. https:// doi.org/10.23919/PICMET.2017.8125348. Accessed 16 July 2019

5. Bowman M, Tomlin JK (2019) Small steps and giant leaps: project apollo- a case study. https://www.projectmanagement. com/videos/564669/Small-Steps-and-Giant-Leaps--ProjectApollo---A-Case-Study. Accessed 16 July 2019

6. Cabri A, Griffiths M (2006) Earned value and agile reporting. In: AGILE 2006 (AGILE'06), IEEE, pp 17-22. DOIurl10.1109/AGILE.2006.21, http://ieeexplore.ieee.org/ document/1667559/

7. Campos J, Ferguson P (2019) Agile space systems management. International Astronautical Congress (IAC), Washington D.C., pp 21-25

8. Campos J, Ferguson P (2020) ManitobaSat-1: space systems engineering for student training. In: Canadian Conference on Electrical and Computer Engineering. https://doi.org/10.1109/ CCECE47787.2020.9255722

9. Carson RS (2013) Can systems engineering be agile? Development lifecycles for systems, hardware, and software. INCOSE Int. Symp. 23(1):16-28. https://doi.org/10.1002/j.2334-5837.2013.tb03001. $\mathrm{x}$

10. CSA (2018) What is the Canadian CubeSat Project. http:// www.asc-csa.gc.ca/eng/satellites/cubesat/what-is-the-canadiancubesat-project.asp. Accessed 8 Feb 2018

11. Doerksen K, Kooster V, Ewout TG (2017) Student Perspectives on the 2017 ESA Concurrent Engineering Challenge. In: Bacsardi L (ed) 2nd Symposium on Space Educational ActivitiesProceedings. Federated Innovation and Knowledge Centre of Budapst University of Technology and Economics, Budapest, pp 249-253

12. Dwyer S (2017) Agile design project methodology for small teams developing mechatronic systems. Thesis, University of Alberta. https://doi.org/10.7939/R38C9RG6T, https://era.library.ualberta. ca/items/38bc534a-eaaa-4e0f-ad7f-2b2c32ba4a7a. Accessed 27 Sep 2018

13. Garzaniti N, Briatore S, Fortin C, Golkar A (2019) Effectiveness of the Scrum Methodology for Agile Development of Space Hardware. In: IEEE Aerospace Conference Proceedings 2019March:1-8. https://doi.org/10.1109/AERO.2019.8741892

14. Graves, E. (2016). Agile for Hardware Development. Boulder, CO: Accuer, Inc

15. Hirshorn, S. (2016). NASA System Engineering Handbook SP2016-6105 Rev2 (2nd ed.). Washington, DC: National Aeronautics and Space Administration

16. Huang PM, Darrin AG, Knuth AA (2012) Agile Hardware and Software System Engineering for Innovation. 2012 IEEE Aerospace Conference. https://doi.org/10.1109/AERO.2012.6187425

17. Jian G, Oriet L (2005) Understanding and implementation of Concurrent Engineering. In: 2005 IEEE International Technology Management Conference (ICE), IEEE, pp 1-4, https://doi.org/10. 1109/ITMC.2005.7461252

18. Larson WJ, Wertz JR (2004) Space mission analysis and design, 3rd edn. Microcosm Press, El Segundo

19. Miller, GL. (2005). Critical chain project management applied to the development of space systems. Collection of Technical Papers. In: AIAA Space 2005 Conference and Exposition, 1345-1351. Long Beach, CA: American Institute of Aeronautics and Astronautics

20. Pate-Cornell E, Dillon R (1998) Challenges in the management of faster-better-cheaper space missions. In: 1998 IEEE Aerospace Conference Proceedings (Cat. No.98TH8339), IEEE, Aspen, CO, USA, vol 5, pp 507-514. https://doi.org/10.1109/AERO.1998. 685861

21. Petrini S, Muniz J (2014) Scrum management approach applied in aerospace sector. In: Conference and Expo of the Institute of Industrial Engineers. Montreal, Canada, pp 434-456

22. Project Management Institute (2017) Project management body of knowledge: a guide to the project management body of knowledge, 6th edn. Project Management Institute, Inc. https://doi.org/ 10.1002/pmj.20125, arXiv:1011.1669v3

23. Reinertsen D (1997) Managing the design factory: a product developer's toolkit, 1st edn. Simon and Schuster Inc, New York

24. Richards CL (2015). A New Space Architecture. AIAA SPACE Conference and Exposition 2015, 3, 3-11. Pasadena, California

25. Rubenstein-Montano B, Liebowitz J, Buchwalter J, McCaw D, Newman B, Rebeck K (2001) A systems thinking framework for knowledge management. Decis Sup Syst 31(1):5-16. https://doi. org/10.1016/S0167-9236(00)00116-0

26. Sauser BJ, Reilly RR, Shenhar AJ (2009) Why projects fail? How contingency theory can provide new insights-a comparative analysis of NASA's Mars Climate Orbiter loss. Int J Project Manag. https://doi.org/10.1016/j.ijproman.2009.01.004

27. Seamans RC Jr Project apollo: the tough decisions. National Aeronautics and Space Administration, Washington, DC. https://doi. org/10.1017/CBO9781107415324.004, arXiv:1011.1669v3

28. Yahyaabadi A, Driedger M, Turenne N, Connell S, Parthasarathy V, Carvey A, Platero V, Campos J, Rososhansky M, Ferguson P (2020) ManitobaSat-1: a novel approach for technology advancement. IEEE Potent 39(4):17-23. https://doi.org/10.1109/MPOT. 2020.2986093

29. Zhanli LI (2020) A brief analysis of the defects and countermeasures of EVM in project management. J Physi Confe Ser. https:// doi.org/10.1088/1742-6596/1648/4/042095

30. Zurbuchen TH, Lal B (2016). Achieving Science with Cubesats: Thinking Inside the Box. Proceedings of the International Astronautical Congress, IAC. Beijing, China 